Original Article

\title{
CORROSION INHIBITION PROPERTY OF EXPIRED FLUOXYMESTERONE DRUG ON THE ALUMINUM (AL) SURFACE IN 3 \% NaCI SOLUTION
}

\author{
NARASIMHA RAGHAVENDRA*, LEENA V. HUBLIKAR, ANJALI S. BHINGE, POOJA J. GANIGER \\ Department of Chemistry, K. L. E. Society's P. C. Jabin Science College (Autonomous) Vidyanagar, Hubballi-580031, India \\ Email: rcbhat3@gmail.com
}

Received: 15 Feb 2019, Revised and Accepted: 11 Apr 2019

\begin{abstract}
Objective: Aluminum (Al) corrosion in the $\mathrm{NaCl}$ solution is an example of dissolution in the neutral medium. The ongoing corrosion research efforts to produce the eco-friendly corrosion inhibitors to protect the aluminum metal from the corrosive solution.

Methods: Herein, mass loss and atomic absorption spectroscopy (AAS) techniques were conducted to explain the adsorption property of expired Fluoxymesterone drug on the $\mathrm{Al}$ surface in the $3 \% \mathrm{NaCl}$ solution.

Results: All results show that the expired Fluoxymesterone drug molecules generate a stable invisible layer through adsorption mechanism on the electrode surface. The corrosion inhibition behavior mainly depends on the concentration of the expired Fluoxymesterone drug and contact time at
\end{abstract} $313 \mathrm{~K}$.

Conclusion: The corrosion inhibition property is due to adsorption of electron-rich molecules on the $\mathrm{Al}$ surface in $3 \% \mathrm{NaCl}$ solution.

Keywords: Aluminum, Mass loss, Expired Fluoxymesterone drug, Contact time, Atomic absorption spectroscopy

(C) 2019 The Authors. Published by Innovare Academic Sciences Pvt Ltd. This is an open-access article under the CC BY license (http://creativecommons.org/licenses/by/4.0/)

DOI: http://dx.doi.org/10.22159/ijcpr.2019v11i3.34100

\section{INTRODUCTION}

Petroleum and other industries produce fuels and other products. Most of the oil and gas pipelines are made from the aluminum. Neutral solutions are widely employed in the industry for pickling, oil well acidizing and cleaning. The corrosion phenomenon for aluminum metal is prominent in these operations [1-3]. Hence, the search for the chemical species which can slow down the metal dissolution process is a never-ending task [4-7]. Therefore, much attention devoted to the synthesis, design and examination of a large number of species possessing $\mathrm{P}, \mathrm{S}, \mathrm{N}$ and $\mathrm{O}$ atoms. However, use of organic compounds as corrosion inhibitors has been restricted because of cost and toxic nature [8-10]. Hence, nowadays research focus shifted towards use of expired drug species as corrosion inhibitors. Medicinal compounds are important organic species possessing a wide range of pharmacological and biological properties. Expired drug products are not useful to the consumers, but, retains its potential property. Hence, in current research, selected expired Fluoxymesterone drug. The corrosion inhibition property of expired Fluoxymesterone drug was thoroughly examined by weight loss (mass loss) and atomic absorption spectroscopy (AAS) techniques at $313 \mathrm{~K}$.

\section{MATERIALS AND METHODS}

\section{Experimental section}

The $99 \%$ aluminum was used in the present research. The Al electrode was mechanically abraded with different grades of emery papers and cleaned thoroughly. Expired Fluoxymesterone drug of four different amounts, namely $0.1 \mathrm{mg} / \mathrm{l}, 0.2 \mathrm{mg} / \mathrm{l}, 0.3 \mathrm{mg} / \mathrm{l}$ and 0.4 $\mathrm{mg} / \mathrm{l}$ were prepared. The $3 \% \mathrm{NaCl}$ solution prepared as per the standard procedure. Weight loss (mass loss) experiment was carried out with $100 \mathrm{ml}$ of $3 \% \mathrm{NaCl}$ solution on the $\mathrm{Al}$ surface as per the ASTM standard at $313 \mathrm{~K}$ with an immersion time of 5, 10, 15 and 20 h. After each test, the Al specimens were taken out from the corrosive solution, rinsed with double distilled water, dried and weighed accurately with the help of analytical digital balance. The experiment was carried out with three times and average values are recorded. Atomic absorption spectroscopy (AAS) experiment was carried out in order to support the weight loss results. The atomic absorption spectroscopy (AAS) experiment was performed at $313 \mathrm{~K}$ with an immersion period of five hours.

\section{RESULTS AND DISCUSSION \\ Weight loss (mass loss) technique}

The results derived from the mass loss (weight loss) technique were summed up in the table 1 and fig. 1 . The introduction of small amounts of inhibitor did not significantly reduce the corrosion rate of the Al. In contrast, the corrosion inhibitive behavior was more pronounced at higher amounts of inhibitor. As the concentration of expired Fluoxymesterone drug enhanced, more corrosion inhibition behavior could be gained in the concentration-dependent mode. At higher concentration, expired Fluoxymesterone drug molecules strongly interact with the Al metal, at higher amounts of expired Fluoxymesterone drug molecules, more and more expired drug species enter the double layer by replacing the water species. Hence, maximum protection behavior observed at $0.4 \mathrm{mg} / \mathrm{l}$ of expired Fluoxymesterone drug. The increase in the time of $\mathrm{Al}$ metal in the 3 $\% \mathrm{NaCl}$ solution enhances the attack of corrosive ions on the surface of $\mathrm{Al}$ in the $3 \% \mathrm{NaCl}$ solution. At higher immersion period, the desorption process overtakes the adsorption process. The corrosive ions degrade the protective layer on the Al surface in the studied system.

These phenomena more pronounced at higher immersion period suggesting that many $\mathrm{Al}$ active sites are blocked by corrosive ions due to an attack of aggressive chemical. As a result of this, $\mathrm{Al}$ weight loss increases with immersion time. Hence, protection efficiency decreases with a rise in the contact time.

\section{Atomic absorption spectroscopy (AAS) technique}

The results of atomic absorption spectroscopy (AAS) are shown in the table 2 and fig. 2 . With a rise in the concentration of expired Fluoxymesterone drug species, Al surface area available for the corrosive reaction is greatly reduced and attack of corrosive ions to the surface of Al became more difficult. At low amounts of expired Fluoxymesterone drug species, a gradual decrease in the $\mathrm{Al}$ dissolution rate was observed. While at high amounts of expired Fluoxymesterone drug species, a significant reduction in the $\mathrm{Al}$ 
corrosion rate (increase in protection efficiency) was observed. This is due to the presence of a thick invisible protective layer on the $\mathrm{Al}$ surface. The invisible layer blocks the motion of corrosive ions towards active Al sites. The protection efficiency obtained from the atomic absorption spectroscopy (AAS) was in good agreement with the weight loss (gravimetric) protection efficiency values [fig. 3].

Table 1: Weight loss results

\begin{tabular}{|c|c|c|}
\hline Concentration (mg/l) & Contact time (h) & Protection (corrosion inhibition) efficiency \\
\hline Bare & 5 & \\
\hline 0.1 & & 60.332 \\
\hline 0.2 & & 62.654 \\
\hline 0.3 & & 72.271 \\
\hline 0.4 & & 98.017 \\
\hline Bare & 10 & \\
\hline 0.1 & & 52.504 \\
\hline 0.2 & & 60.007 \\
\hline 0.3 & & 70.018 \\
\hline 0.4 & & 85.903 \\
\hline Bare & 15 & \\
\hline 0.1 & & 50.086 \\
\hline 0.2 & & 55.805 \\
\hline 0.3 & & 67.805 \\
\hline 0.4 & & 75.063 \\
\hline Bare & 20 & \\
\hline 0.1 & & 43.706 \\
\hline 0.2 & & 52.358 \\
\hline 0.3 & & 58.573 \\
\hline 0.4 & & 67.112 \\
\hline
\end{tabular}

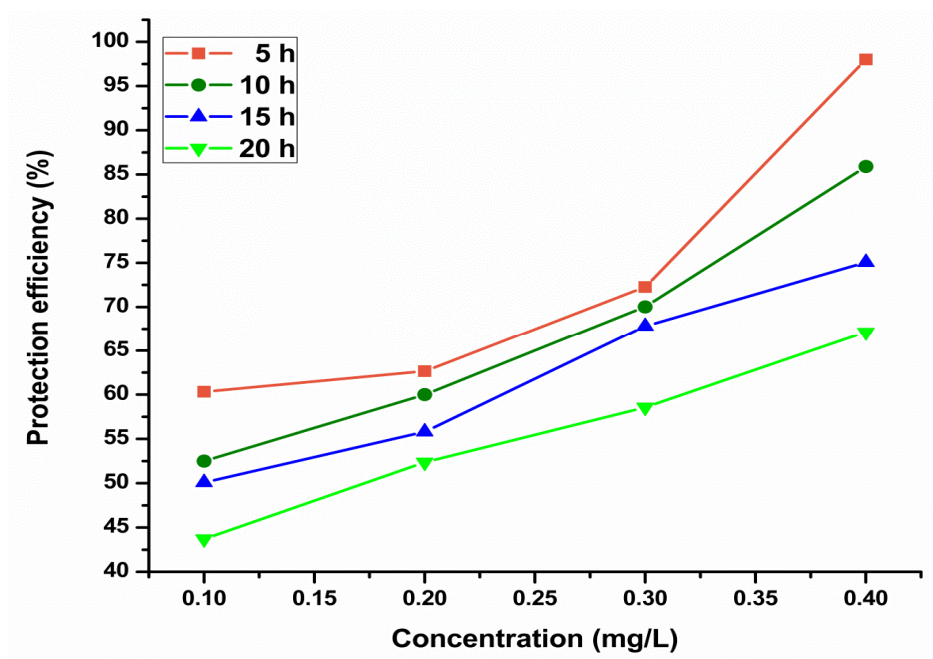

Fig. 1: Protection efficiency values obtained from weight loss technique

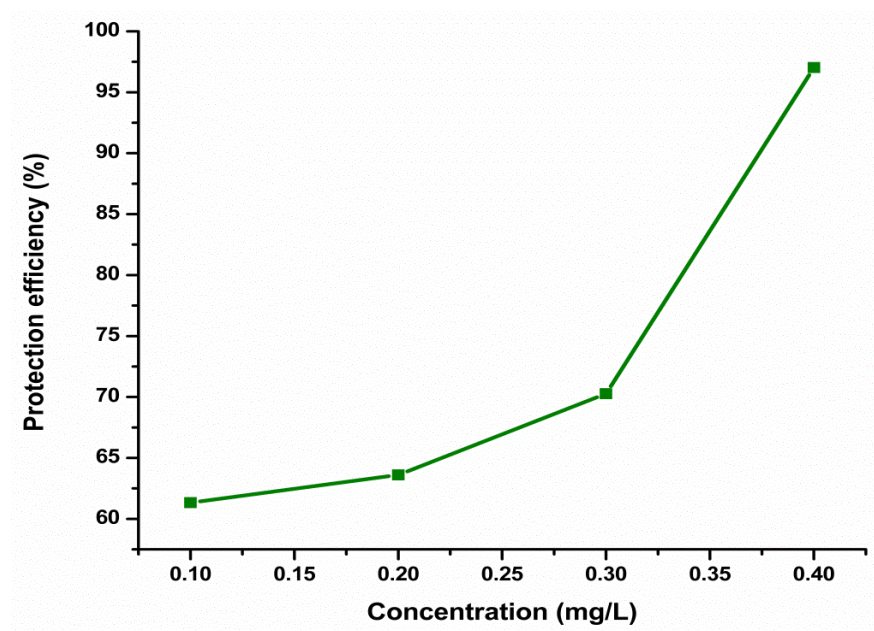

Fig. 2: Protection efficiency versus concentration (mg/l) 
Table 2: Atomic absorption spectroscopy results

\begin{tabular}{ll}
\hline Concentration $(\mathbf{m g} / \mathbf{l})$ & Protection (corrosion inhibition) efficiency \\
\hline 0.1 & 61.330 \\
0.2 & 63.612 \\
0.3 & 70.270 \\
0.4 & 97.027 \\
\hline
\end{tabular}

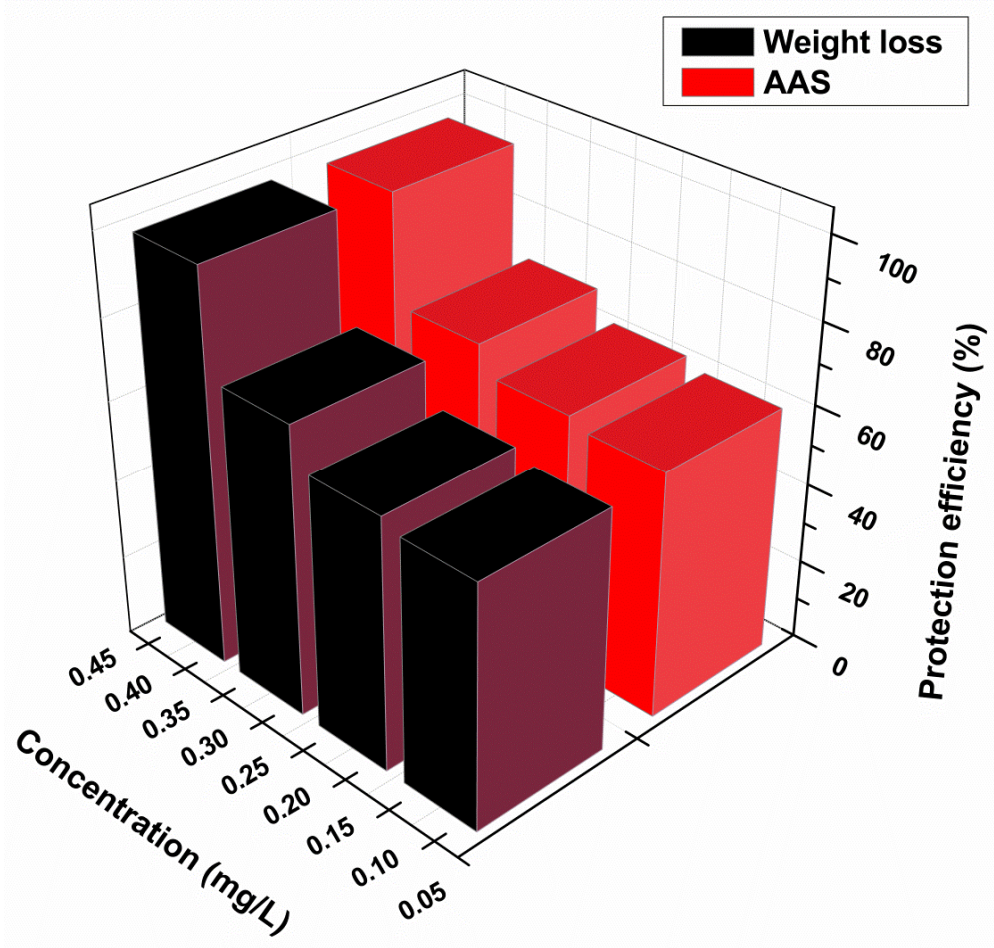

Fig. 3: Results of weight loss and AAS

\section{CONCLUSION}

In summary, this study investigated the corrosion inhibition effect of expired Fluoxymesterone drug species on the Al corrosion in $3 \%$ $\mathrm{NaCl}$ solution. An experimental approach was done through weight loss (gravimetric) and atomic absorption spectroscopy (AAS) techniques. The chemical (weight loss) results illustrate that, expired Fluoxymesterone drug act as good corrosion inhibitor with time and concentration-dependent mode. At higher contact time, desorption process dominates the adsorption process. Atomic absorption spectroscopy (AAS) results give a clear hint about the corrosion inhibition property of expired Fluoxymesterone drug. The results of the chemical study are in good agreement with the atomic absorption spectroscopy results.

\section{AUTHORS CONTRIBUTIONS}

All the author have contributed equally

\section{CONFLICT OF INTERESTS}

Declare none

\section{REFERENCES}

1. Hassane Lgaz, Abdelkarim Chaouiki, Mustafa R Albayati, Rachid Salghi, Yasmina El Aoufir, Ismat $\mathrm{H}$ Ali, et al. Synthesis and evaluation of some new hydrazones as corrosion inhibitors for mild steel in acidic media. Res Chem Intermed 2019;45:2269-86.

2. Raghavendra N, Ishwara Bhat J. Green approach to inhibition of corrosion of aluminum in $0.5 \mathrm{M} \mathrm{HCl}$ medium by tender arecanut seed extract: insight from gravimetric and electrochemical studies. Res Chem Intermed 2016;42:6351-72.

3. Diggle W, Downie TC, Goulding C. The dissolution of porous oxide films on aluminum. Electrochim Acta 1970;15:1079-93.

4. Pyun SI, Moon SM. The inhibition mechanism of pitting corrosion of pure aluminium by nitrate and sulfate ions in neutral chloride solution. J Solid State Electrochem 1999;3:331-6.

5. Abdallah M. Antibacterial drugs as corrosion inhibitors for corrosion of aluminium in hydrochloric solution. Corros Sci 2004;46:1981-96.

6. Ferreira ES, Giacomelli C, Giacomelli FC, Spinelli A. Evaluation of the inhibitor effect of L-ascorbic acid on the corrosion of mild steel. Mater Chem Phys 2004;83:129-34.

7. Fouda AS, Megahed HE, Fouad N, Elbahrawi NM. Corrosion inhibition of carbon steel in $1 \mathrm{M}$ hydrochloric acid solution by aqueous extract of Thevetia peruviana. J Bio Tribo Corrosion 2016;2:16.

8. Zheludkevich ML, Yasakau KA, Poznyak SK, Ferreira MGS. Triazole and thiazole derivatives as corrosion inhibitors for AA2024 aluminium alloy. Corros Sci 2005;47:3368-83.

9. Deng $\mathrm{S}, \mathrm{Li} \mathrm{X}$. The synergistic inhibitive effect and some quantum chemical parameters of 2,3-diaminonaphthalene and iodide ions on the hydrochloric acid corrosion of aluminium. Corros Sci 2012;64:253-62.

10. Rosaliza R, Wan Nik WB, Senin HB. The effect of inhibitor on the corrosion of aluminum alloys in acidic solutions. Mater Chem Phys 2008;107:281-8. 